\title{
DNA Marker Based Characterization of Wheat Genotypes for Terminal Heat Tolerance
}

\author{
Amarjeet Kumar*, Swati, Narendra Kumar Singh, Anil Kumar and Jai Prakash Jaiswal \\ Department of Genetics and Plant Breeding, College of Agriculture, G. B. Pant University of \\ Agriculture and Technology, Pantnagar-263145, Udham Singh Nagar, Uttarakhand, India \\ *Corresponding author
}

\begin{tabular}{|l|}
\hline Ke y w or d s \\
$\begin{array}{l}\text { DNA marker, } \\
\text { Wheat genotypes, } \\
\text { Terminal heat } \\
\text { tolerance }\end{array}$ \\
\hline Article Info \\
\hline $\begin{array}{l}\text { Accepted: } \\
\text { 20 February } 2018 \\
\text { Available Online: } \\
\text { 10 March } 2018\end{array}$ \\
\hline
\end{tabular}

\section{A B S T R A C T}

In India, wheat is cultivated on around 29.8 mha that produces $92.5 \mathrm{mt}$ with an average productivity of $3.1 \mathrm{t} / \mathrm{ha}$. But in recent scenario of climate change our wheat cultivars succumb to the grave problem of terminal heat stress leading to substantial reduction in its production and productivity. Sixteen genotypes of wheat were used for assessing the molecular diversity for terminal heat stress tolerance against 14 SSR markers linked to the trait of interest. Results revealed that amplified alleles ranged from $185 \mathrm{bp}$ to $230 \mathrm{bp}$. The maximum number of polymorphic bands was generated with primers Xgwm 484 and Xcfd 43 that resulted in 4 amplicons followed by primer Xgwm 268 that resulted in 3 amplicons. The SSR primer Xgwm 484 amplified 4 polymorphic amplicons varying from size $220 \mathrm{bp}$ to $230 \mathrm{bp}$. The marker Xcfd 43 detected 4 SSR alleles. The dendrogram classified sixteen genotypes into two broad groups, A and B. The two groups were generated at a similar coefficient of 0.55 . Group A consisted of six genotypes and was further subdivided into three clusters. Group B consisted of ten genotypes which were further subdivided into three clusters (cluster IV, V and VI). The mean HSI, grain yield and relative reduction in grain yield under stress condition over timely sown condition was the basis of categorization of genotypes correspond to the molecular data. Genotypes, DBW90, WH1021, HD3059, JOB666, UP2843 and WH1124 have proved their suitability for late sown condition out of which the former three genotypes (DBW90, WH1021and HD3059) has already been released for late sown condition.

\section{Introduction}

Wheat (Triticum aestivum L.), a cereal of grass family (Graminae) is the world's largest cereal crop. It has been described as the 'King of cereals' because of the acreage it occupies, high productivity and the prominent position it holds in the international food grain trade. It ranks first among cereals in production, constitutes the staple food of about $36 \%$ of the world population and contributes almost one-third to the total food grain in India. The world acreage under wheat crop is around 215.26 mha with a production of 717.1 million-tons (Mt) with an average yield of $2.99 \mathrm{t} / \mathrm{ha}$. India ranks second largest producer of wheat with $13.43 \%$ global wheat production share after China. In India, it is cultivated on around 29.8 mha that produces $92.5 \mathrm{mt}$ with an average productivity of 3.1 
t/ha (USDA Foreign Agricultural service, Grain Report 2014). But in recent scenario of climate change our wheat cultivars succumb to the grave problem of terminal heat stress leading to substantial reduction in its production and productivity. So the development of varieties that can well mitigate the adverse effect of terminal drought leaving a bare minimal impact on yield performance of varieties can be a thrust to boost the production and productivity of wheat in our country (Reynolds and Borlaug, 2006). In India, incidences of high temperatures at the time of grain-filling are more pronounced when sowing of wheat is delayed (Rane et al., 2007 and Joshi et al., 2007). It was found that a $2^{\circ} \mathrm{C}$ increase above long-term averages shortened the growing season by a critical nine days, reduced total yield by up to 50 percent (Lobell et al., 2012). The relationship between the morpho-physiological traits associated with heat tolerance is very much important in selection criteria for heat tolerance. Several approaches should be actively exploited to improve heat tolerance in current cultivars including discovery and exploitation of new genes and alleles, improved breeding efficiency, marker assisted selection and genetic modification. Genetic diversity for heat tolerance in wheat is well established (Wardlaw et al., 1989 and Reynolds et al., 2001). Therefore, the heat tolerant wheat variety is still one of the priorities of agricultural research, because above the optimum temperature $\left(21.3 \pm 1.27^{\circ} \mathrm{C}\right)$ wheat yield is drastically affected. Therefore, there is a dire need to develop/identify genotypes that are either tolerant to terminal heat stress or that mature early without appreciable yield losses.

So far, there are no direct selection criteria to evaluate heat tolerance since heat tolerance is the complex of many traits which are under the influence of different sets of genes (Blum, 1988; Howarth, 2005; Bohnert et al., 2006).
Simple sequence repeats, also called microsatellites, and were interspersed ubiquitously in the DNA of hexaploid wheat (Roder et al., 1998). Molecular and genetic approaches to study the DNA polymorphism conferring thermo-tolerance will not only facilitate marker-assisted breeding for heat tolerance but also pave the way for cloning and characterization of underlying genetic factors which could be useful for engineering plants with improved heat tolerance.

\section{Materials and Methods}

\section{Plant material}

Sixteen genotypes of wheat were used for assessing the molecular diversity for terminal heat stress tolerance against 14 SSR markers linked to the trait of interest (Sadat et al., 2013). The genotypes were evaluated under field conditions at Norman E. Borlaug Crop Research Centre during rabi2014-15in Randomized Block Design (RBD) with three replications. Various morpho-physiological data pertaining to heat stress was recorded. The lab experiment was conducted in wheat Laboratory, Department of Genetics and Plant Breeding, G. B. Pant University of Agriculture and Technology.

\section{Genomic DNA extraction}

The genomic DNA from each genotype was isolated from young healthy leaves of 30 days old seedlings. DNA was extracted using CTAB (Cetyltrimethyl ammonium bromide) method as described by Chakraborti et al., (2006).

The quality of DNA was assessed by gel electrophoresis (8\% agarose) and quantity was estimated by using spectrophotometer. RNAse treated DNA samples were diluted to a working concentration of $100 \mathrm{ng} / \mu \mathrm{l}$ and stored for further PCR amplification. 


\section{PCR amplification and gel electrophoresis}

Fourteen SSR primers (Table 1) reported earlier to be linked to heat stress was synthesized from VBC Biotech Ltd. The original source, repeat motifs, primer sequences and chromosomal position of these markers can be found in the http://wheat.pw.usda.gov.

Amplifications were performed in a $25 \mu 1$ reaction mixture containing $2.5 \mu \mathrm{l} \mathrm{Taq}$ buffer (1X) containing [10mM Tris- $\mathrm{HCl}(\mathrm{pH} 8.3), 50$ $\left.\mathrm{mMKCl}, 2.5 \mathrm{mM} \mathrm{MgCl}_{2}\right], 0.8 \mathrm{mM}$ of dNTPs, $0.04 \mu \mathrm{M}$ of each forward and reverse primers, $100 \mathrm{ng}$ genomic DNA and 3 units/ $\mu \mathrm{l}$ Taq DNA polymerase. The PCR reaction was performed in an Eppendorf Master Cycler gradient (Eppendorf Netheler-Hinz, Hamburg, Germany). The PCR cycle conditions for SSR markers were as follows: for amplification in the first cycle, initial denaturation was conducted at $94^{\circ} \mathrm{C}$ for $5 \mathrm{~min}$ then at $94^{\circ} \mathrm{C}$ for $1 \mathrm{~min}$. Then it was followed by annealing at $55^{\circ} \mathrm{C}$ for $2 \mathrm{~min}$ and extension at $72^{\circ} \mathrm{C}$ for 2 min. The cycle was repeated 35 times followed by a final extension for $10 \mathrm{~min}$ at $72^{\circ} \mathrm{C}$. The amplicons generated were resolved on $2.5 \%$ agarose gel using horizontal gel electrophoresis assembly. After $75 \%$ of the gel run, the amplicons were visualized and photographed under UV light (Alpha Innotech Corporation, USA).

\section{Molecular data analysis}

The presence of ampliconson agarose gel was taken as one and absence of amplicons was read as zero. The $0 / 1$ matrix was used to calculate similarity genetic distance using 'simqual' sub-program of software NTSYSPC (Rohlf, 1990). Dendrogram was constructed by using distance matrix by the unweighted pair-group method with arithmetic average (UPGMA) sub-programme of NTSYS-PC. Principle component analysis
(PCA) was done using the 'CPCA' sub programme of NTSYS-PC.

\section{Results and Discussion}

Out of 14 SSR primers used in our study only three primers showed polymorphism whereas nine primers gave monomorphic bands. A total of 11 bands were generated for the 16 genotypes with an average of 3.6 alleles per primer. The summary of results exhibited by primers is presented in Table 1. Banding patterns of 16 wheat genotypes generated by primers viz., Xgwm 268, Xgwm 484 and Xcfd 43 are presented in figure 1, 2, 3 respectively. Results revealed that amplified alleles ranged from $185 \mathrm{bp}$ to $230 \mathrm{bp}$. The maximum number of polymorphic bands was generated with primers Xgwm484and Xcfd 43 that resulted in 4 amplicons followed by primer Xgwm 268 that resulted in 3 amplicons. The SSR primer Xgwm 484 amplified 4 polymorphic amplicons varying from size $220 \mathrm{bp}$ to $230 \mathrm{bp}$. The marker Xcfd 43detected 4 SSR alleles. All the four alleles were found to be polymorphic and SSR amplicons varied in size from $195 \mathrm{bp}$ to $205 \mathrm{bp}$. The marker Xgwm 268 resulted in 3 polymorphic amplicons varying from size $220 \mathrm{bp}$ to $230 \mathrm{bp} .185 \mathrm{bp}$ to 190 bp. The UPGMA (Unweighted Pair Group Method with Arithmetic mean) was constructed using Jaccard's similarity coefficients of SSR marker data generated on 16 genotypes (Table $2-4$ ).

The dendrogram classified sixteen parental lines into two broad groups, A and B. The two groups were generated at a similar coefficient of 0.55. Group A consisted of six genotypes and was further subdivided into three clusters. Cluster I consisted of only one genotype, HD3091, having HSI value of 1.10 and $6.93 \mathrm{~g}$ grain yield per plant in stress condition (E2).this genotype suffered $65.12 \%$ decrease in mean grain yield in E2 in comparison to that in normal environment (E1). This 
genotype is close to the members of cluster II of group A by a similarity A by similarity coefficient of 0.56. Cluster II consisted of three genotypes namely CBW12, HD2329 and HD2961.HSI and grain yield/plant (g) and reduction in mean yield compared to the normal unstressed condition (\%) was observed in range of $0.94-1.21,6.57-7.47$ and 56.5768.68 in order. The cluster means for HSI, grain yield per plant and percentage decrease were 1.1, 6.81 and 65.39, respectively. These 3 genotypes of cluster II were found close to the members of cluster III of group A by a similarity coefficient of 0.73. However, Cluster III comprised of two genotypes viz. HD2967 and WH1105. The mean HSI, grain yield and relative reduction in grain yield under stress condition for this cluster was observed to be $1.15,7.46 \mathrm{~g}$ and $68.77 \%$ respectively. Group B consisted of ten genotypes which were further subdivided into three clusters (cluster IV, V and VI). Cluster IV included six genotypes viz. JOB666, DBW90, HPW211, WH1021, WH1124 and UP2843. Among these genotypes, JOB666, DBW90, HPW211 and WH1021 have showed higher similarity coefficient of 1.0. Cluster V consisted of two genotypes viz. HD3059 and MACS6272. Both these clusters are related by a similarity coefficient of 0.73 . However, Cluster VI included two genotypes viz. WAXWING and HD2891 having high similarity coefficient of 1.0. The results were in agreement with the results of Ali et al., (2012), Pinto et al., (2010) and Sadat et al., (2013) who used SSR markers for assessing the genetic diversity for heat stress tolerance in wheat.

Cluster wise mean values of HSI, mean grain yield in late sown condition and mean percentage decrease or increase in grain yield in late sown over timely sown condition as well as the values of same parameters for each member of the cluster are presented in Table 3. In Group B, cluster IV consisting of 6 genotypes showed a range of 6.93-10.70 $\mathrm{g}$ for grain yield per plant, $0.69-0.93$ for HSI and $41.29-54.75 \%$ decrease in grain yield as compared to that of timely sown condition. The cluster means for the respective traits were 8.67, 0.86 and 51.97 respectively. The two genotypes in cluster $\mathrm{V}$ showed mean grain yield of $10.67 \mathrm{~g}$ under stress, mean HSI of 0.77 and $46.33 \%$ decrease in grain yield. Likewise, mean value of 10.11, 0.96 and $57.63 \%$ were exhibited for grain yield (g), HSI and percent decrease for the two genotypes clustered in cluster VI of group B. The two major groups obtained in cluster analysis differed with respect to three parameters as a measure of heat tolerance at field level viz., HSI, grain yield in stress and percent decrease in grain yield in stress over normal condition as evident from the table 3 .

Perusal of all the six clusters showed that cluster III had highest mean HSI value as well as highest decrease in grain yield under late sown condition over timely sown condition. The genotypes HD2967 and WH1105 that belongs to cluster III has already been released as variety for timely sown condition as these are not able to cope up with terminal heat stress and are heat sensitive. However, HD2967 has genetic potential for higher yield as evident from its higher yield under stress as compared to other genotypes of group A. The molecular grouping of WH1105 as heat sensitive genotype is justified by higher HSI value and its lowest yield under late sown condition.

HD2329 has been found to be a heat sensitive genotype in our molecular analysis that conforms to the earlier findings of Sairam et al., (2001). Similarly, molecular characterization of HD3091 and CBW12 places them in the heat sensitive group, supported by higher HSI value, low grain yield and higher percentage decrease in grain yield. 
Table.1 Characteristics of 14 linked SSR markers used in characterization

\begin{tabular}{|l|l|l|l|c|}
$\mathbf{5 .} \mathbf{N}$ & \multicolumn{1}{|c|}{ Marker } & \multicolumn{1}{|c|}{ Primers sequence Reverse (5'- 3') } & \multicolumn{1}{|c|}{ Primers sequence Forward (5' - 3') } & $\begin{array}{c}\text { Annealing temp. } \\
\left(\mathbf{(}^{\circ} \mathbf{C}\right)\end{array}$ \\
\hline $\mathbf{1}$ & gwm11 & GTGAATTGTGTCTTGTATGCTTCC & GGATAGTCAGACAATTCTTGTG & 50 \\
\hline $\mathbf{2}$ & Xcfd43 & CCAAAAACATGGTTAAAGGGG & AACAAAAGTCGGTGCAGTCC & 60 \\
\hline $\mathbf{3}$ & Xgwm356 & CCAATCAGCCTGCAACAAC & AGCGTTCTTGGGAATTAGAGA & 55 \\
\hline $\mathbf{4}$ & Xbarc137 & CCAGCCCCTCTACACATTTT & GGCCCATTTCCACTTTCA & 52 \\
\hline $\mathbf{5}$ & Gwm484 & AGTTCCGGTCATGGCTAGG & ACATCGCTCTTCACAAACCC & 55 \\
\hline $\mathbf{6}$ & Gwm293 & TCGCCATCACTCGTTCAAG & TACTGGTTCACATTGGTGCG & 55 \\
\hline $\mathbf{7}$ & gwm291 & AATGGTATCTATTCCGACCCG & CATCCCTAGGCCACTCTGC & 60 \\
\hline $\mathbf{8}$ & Gwm325 & TTTTACGCGTCAACGACG & TTTCTTCTGTCGTTCTCTTCC & 60 \\
\hline $\mathbf{9}$ & Xgwm294 & GCAGAGTGATCAATGCCAGA & GGATTGGAGTTAAGAGAGAACCG & 55 \\
\hline $\mathbf{1 0}$ & Gwm268 & TTATGTGATTGCGTACGTACCC & AGGGGATATGTTGTCACTCCA & 55 \\
\hline $\mathbf{1 1}$ & Xwmc407 & CATATTTCCAAATCCCCAACTC & GGTAATTCTAGGCTGACATATGCTC & 61 \\
\hline $\mathbf{1 2}$ & Xcfa2129 & ATCGCTCACTCACTATCGGG & GTTGCACGACCTACAAAGCA & 60 \\
\hline $\mathbf{1 3}$ & Xgwm11.2 & ACCTGATCAGATCCCCATCG & TCTGTAGGCTCTCTCCGACTG & 55 \\
\hline $\mathbf{1 4}$ & WMC527 & GCTACAGAAAACCGGAGCCTAT & ACCCAAGATTGGTGGCAGAA & 61 \\
\hline
\end{tabular}

Table.2 Summary of SSR amplified products

\begin{tabular}{|c|l|c|}
\hline S. No. & Specification & Particular \\
\hline $\mathbf{1}$ & Total no. of primers tested & 14 \\
\hline $\mathbf{2}$ & No. of polymorphic primers & 3 \\
\hline $\mathbf{3}$ & No. of monomorphic primers & 9 \\
\hline $\mathbf{4}$ & Total no. of alleles amplified & 11 \\
\hline $\mathbf{5}$ & Size range of amplified alleles in bp & $185-230$ \\
\hline $\mathbf{6}$ & Average no. of alleles per primer & 3.66 \\
\hline
\end{tabular}

Table.3 Summary of wheat genotypes clusters using morpho-physiological traits

\begin{tabular}{|c|c|c|c|c|c|c|c|}
\hline \multirow[t]{2}{*}{ Cluster } & \multirow[t]{2}{*}{ Genotypes } & \multirow[t]{2}{*}{ HSI } & \multirow[t]{2}{*}{ GY } & \multirow{2}{*}{$\begin{array}{c}\text { \% Decrease in } \\
\text { grain yield }\end{array}$} & \multicolumn{3}{|c|}{ Cluster mean } \\
\hline & & & & & HSI & GY & $\%$ \\
\hline \multicolumn{8}{|l|}{ GROUP A } \\
\hline Cluster I & HD3091 & 1.08 & 6.93 & 65.12 & 1.1 & 6.93 & 65.12 \\
\hline Cluster II & CBW12 & 1.21 & 6.40 & 72.65 & \multirow[t]{3}{*}{1.1} & \multirow[t]{3}{*}{6.81} & \multirow[t]{3}{*}{65.39} \\
\hline Cluster II & HD2329 & 1.11 & 6.57 & 66.94 & & & \\
\hline Cluster II & HD2961 & 0.94 & 7.47 & 56.57 & & & \\
\hline Cluster III & HD2967 & 1.09 & 9.4 & 65.48 & \multirow[t]{2}{*}{1.15} & \multirow[t]{2}{*}{7.46} & \multirow[t]{2}{*}{68.77} \\
\hline Cluster III & WH1105 & 1.20 & 5.53 & 72.07 & & & \\
\hline \multicolumn{8}{|l|}{ GROUP B } \\
\hline Cluster IV & JOB666 & 0.93 & 7.87 & 55.96 & \multirow[t]{6}{*}{0.86} & \multirow[t]{6}{*}{8.67} & \multirow[t]{6}{*}{51.97} \\
\hline Cluster IV & DBW90 & 0.69 & 9.20 & 41.29 & & & \\
\hline Cluster IV & HPW211 & 0.91 & 7.47 & 65.94 & & & \\
\hline Cluster IV & WH1021 & 0.90 & 6.40 & 60.49 & & & \\
\hline Cluster IV & WH1124 & 0.91 & 7.40 & 68.68 & & & \\
\hline Cluster IV & UP2843 & 0.84 & 6.93 & 50.50 & & & \\
\hline Cluster V & HD3059 & 0.59 & 12.8 & 35.58 & \multirow[t]{2}{*}{0.77} & \multirow[t]{2}{*}{10.67} & \multirow[t]{2}{*}{46.33} \\
\hline Cluster V & MACS6272 & 0.95 & 8.53 & 57.07 & & & \\
\hline Cluster VI & WAXWING & 1.00 & 9.40 & 60.17 & \multirow[t]{2}{*}{0.96} & \multirow[t]{2}{*}{10.11} & \multirow[t]{2}{*}{57.63} \\
\hline Cluster VI & HD2891 & 0.92 & 10.81 & 55.09 & & & \\
\hline
\end{tabular}


Table.4 Similarity matrix for Jaccard's coefficient for 16 genotypes of wheat

\begin{tabular}{|c|c|c|c|c|c|c|c|c|c|c|c|c|c|c|c|c|}
\hline & $\begin{array}{l}\text { बे } \\
\text { હे } \\
\text { 量 }\end{array}$ & $\begin{array}{l}6 \\
6 \\
0 \\
0\end{array}$ & $\frac{8}{2}$ & 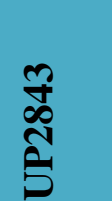 & 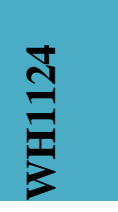 & $\sum^{2}$ & $\frac{\sqrt{2}}{8}$ & $\frac{N}{3}$ & $\begin{array}{l}\text { No } \\
\text { U } \\
\sum_{N}\end{array}$ & ิㅡㄹ & $\begin{array}{l}z \\
z \\
z \\
z\end{array}$ & 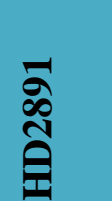 & $\begin{array}{l}\text { 무 } \\
\text { సิ } \\
\text { है }\end{array}$ & $\begin{array}{l}\hat{6} \\
\hat{8} \\
\hat{2}\end{array}$ & $\frac{n}{2}$ & $\begin{array}{l}\text { ㅇ. } \\
\text { సิ } \\
\text { 尺ี }\end{array}$ \\
\hline HD3091 & 1.000 & & & & & & & & & & & & & & & \\
\hline JOB666 & 0.455 & 1.000 & & & & & & & & & & & & & & \\
\hline DBW90 & 0.455 & 1.000 & 1.000 & & & & & & & & & & & & & \\
\hline UP2843 & 0.727 & 0.727 & 0.727 & 1.000 & & & & & & & & & & & & \\
\hline WH1124 & 0.545 & 0.909 & 0.909 & 0.818 & 1.000 & & & & & & & & & & & \\
\hline HPW211 & 0.455 & 1.000 & 1.000 & 0.727 & 0.909 & 1.000 & & & & & & & & & & \\
\hline WH1021 & 0.455 & 1.000 & 1.000 & 0.727 & 0.909 & 1.000 & 1.000 & & & & & & & & & \\
\hline CBW12 & 0.636 & 0.636 & 0.636 & 0.727 & 0.545 & 0.636 & 0.636 & 1.000 & & & & & & & & \\
\hline MACS6272 & 0.636 & 0.818 & 0.818 & 0.727 & 0.727 & 0.818 & 0.818 & 0.818 & 1.000 & & & & & & & \\
\hline HD2329 & 0.636 & 0.455 & 0.455 & 0.727 & 0.545 & 0.455 & 0.455 & 0.818 & 0.636 & 1.000 & & & & & & \\
\hline WAXWING & 0.455 & 0.636 & 0.636 & 0.727 & 0.727 & 0.636 & 0.636 & 0.455 & 0.636 & 0.636 & 1.000 & & & & & \\
\hline HD2891 & 0.455 & 0.636 & 0.636 & 0.727 & 0.727 & 0.636 & 0.636 & 0.636 & 0.636 & 0.636 & 1.000 & 1.000 & & & & \\
\hline HD2961 & 0.455 & 0.455 & 0.455 & 0.727 & 0.545 & 0.455 & 0.455 & 0.636 & 0.455 & 0.818 & 0.636 & 0.636 & 1.000 & & & \\
\hline HD3059 & 0.636 & 0.636 & 0.636 & 0.727 & 0.727 & 0.636 & 0.636 & 0.636 & 0.818 & 0.636 & 0.636 & 0.636 & 0.455 & 1.000 & & \\
\hline WH1105 & 0.636 & 0.455 & 0.455 & 0.727 & 0.545 & 0.455 & 0.455 & 0.818 & 0.636 & 0.818 & 0.455 & 0.455 & 0.636 & 0.818 & 1.000 & \\
\hline HD2961 & 0.455 & 0.455 & 0.455 & 0.727 & 0.545 & 0.455 & 0.455 & 0.636 & 0.455 & 0.636 & 0.636 & 0.636 & 0.636 & 0.636 & 0.818 & 1.000 \\
\hline
\end{tabular}


Fig.4 Dendrogram: clustering of 16 parental genotypes of wheat

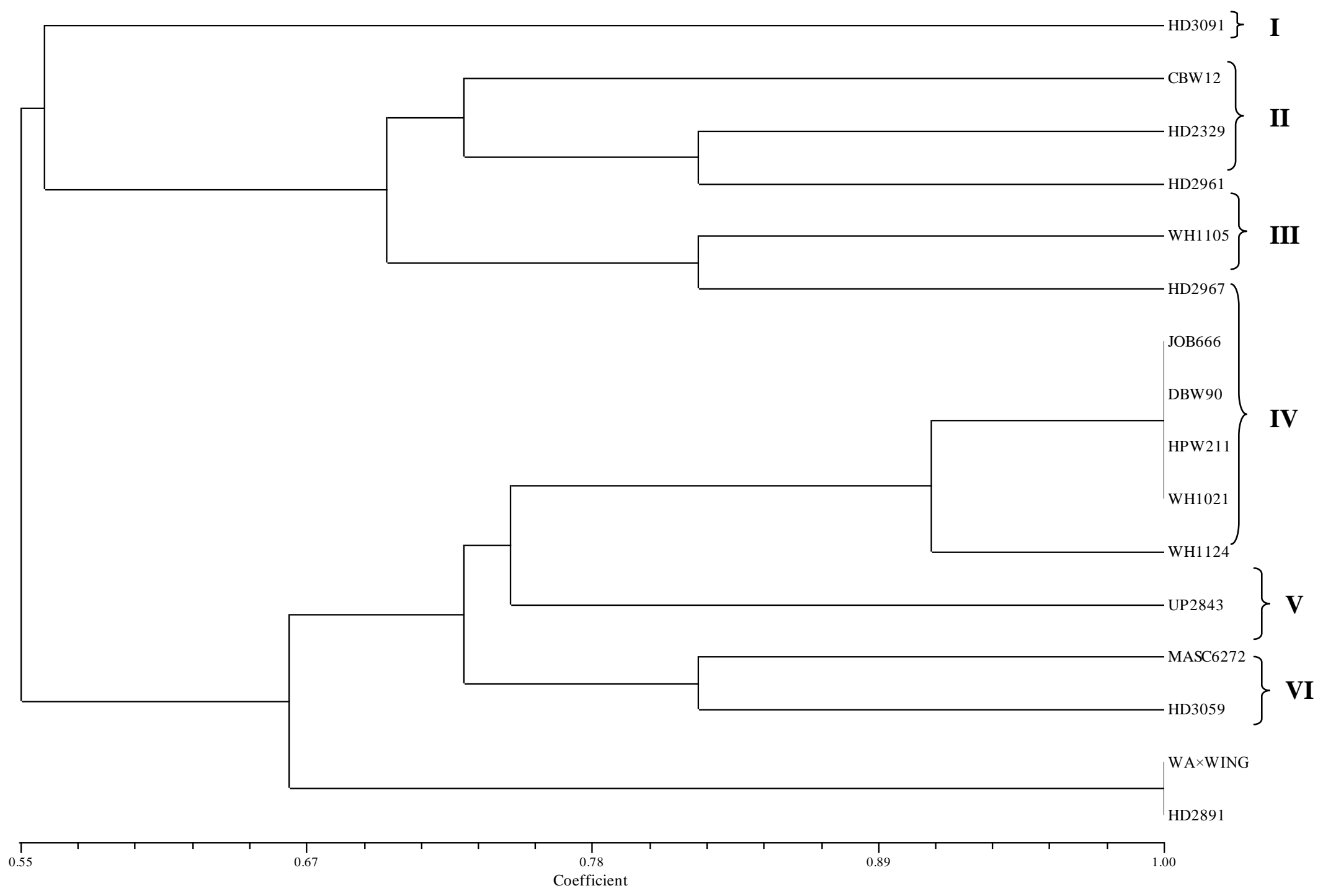


Fig.1 Banding profile of Gwm268 marker among 16 genotypes of bread wheat. Lane M-Ladder; S-HD3091; R-JOB666; 1-DBW90; 2-UP2843; 3-WH1124; 4-HPW211; 5-WH1021; 6-CBW12; 7-MACS6272; 8-HD2329; 9-WAXWING; 10-HD2891; 11-HD2961; 12-HD3059; 13-WH1105; 14-HD2967

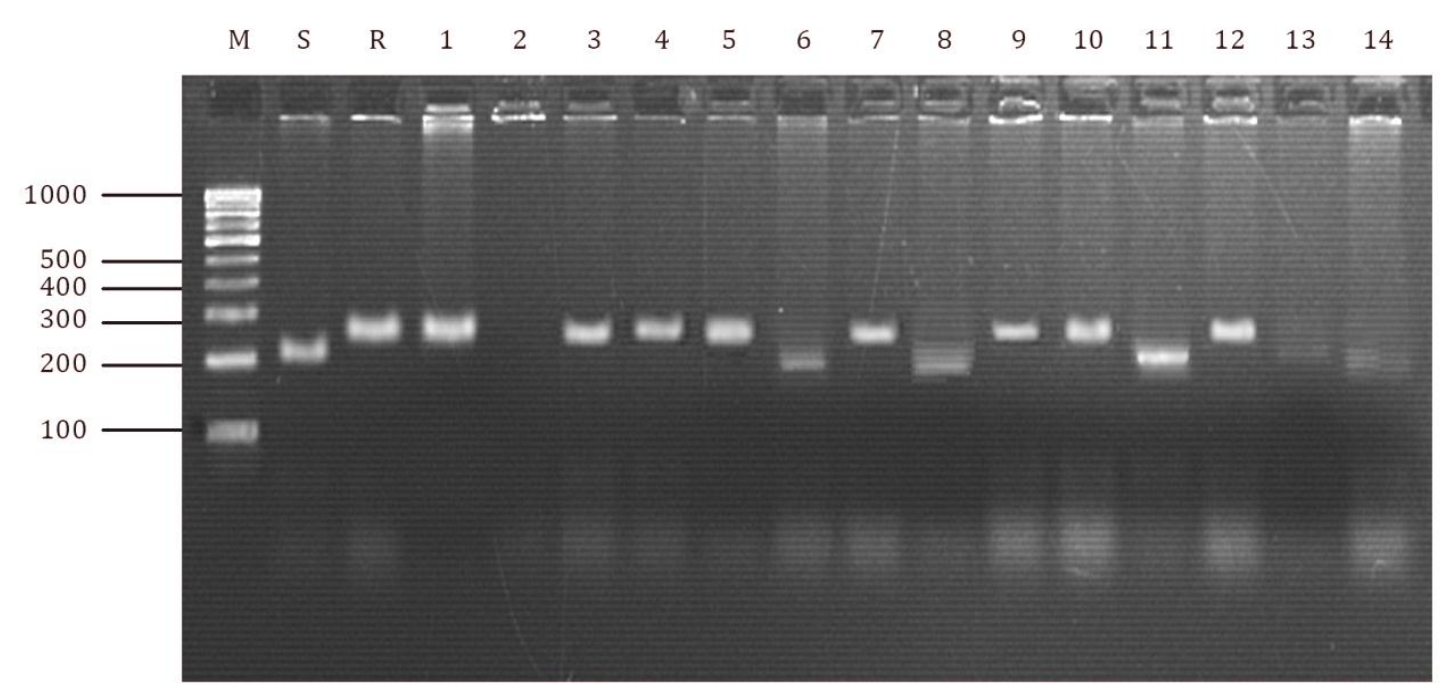

Fig.2 Banding profile of Gwm484 marker among 16 genotypes of bread wheat. Lane M-Ladder; S-HD3091; R-JOB666; 1-DBW90; 2-UP2843; 3-WH1124; 4-HPW211; 5-WH1021; 6-CBW12; 7-MACS6272; 8-HD2329; 9-WAXWING; 10-HD2891; 11-HD2961; 12-HD3059; 13-WH1105; 14-HD2967

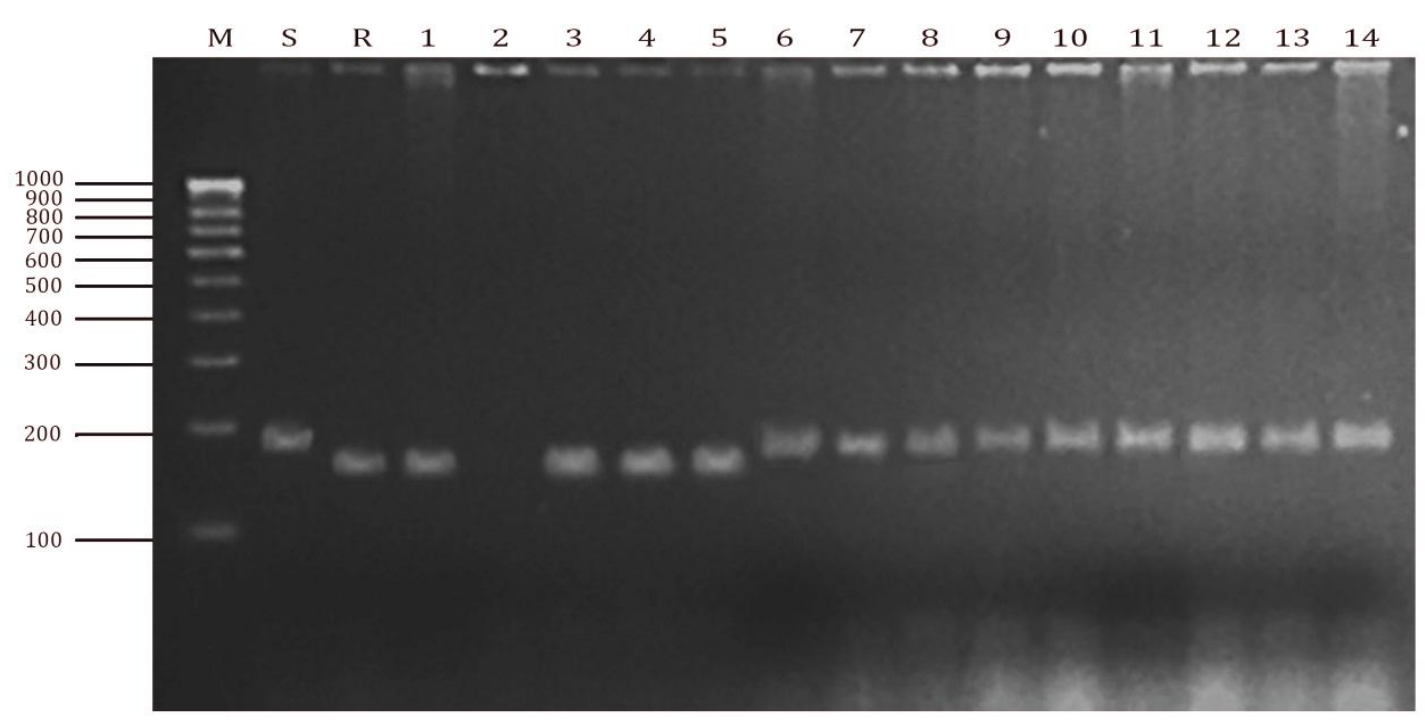


Fig.3 Banding profile of Xcfd43 marker among 16 genotypes of bread wheat. Lane M-Ladder; S-HD3091; R-JOB666; 1-DBW90; 2-UP2843; 3-WH1124; 4-HPW211; 5-WH1021; 6-CBW12; 7-MACS6272; 8-HD2329; 9-WAXWING; 10-HD2891; 11-HD2961; 12-HD3059; 13-WH1105;

\section{4-HD2967}

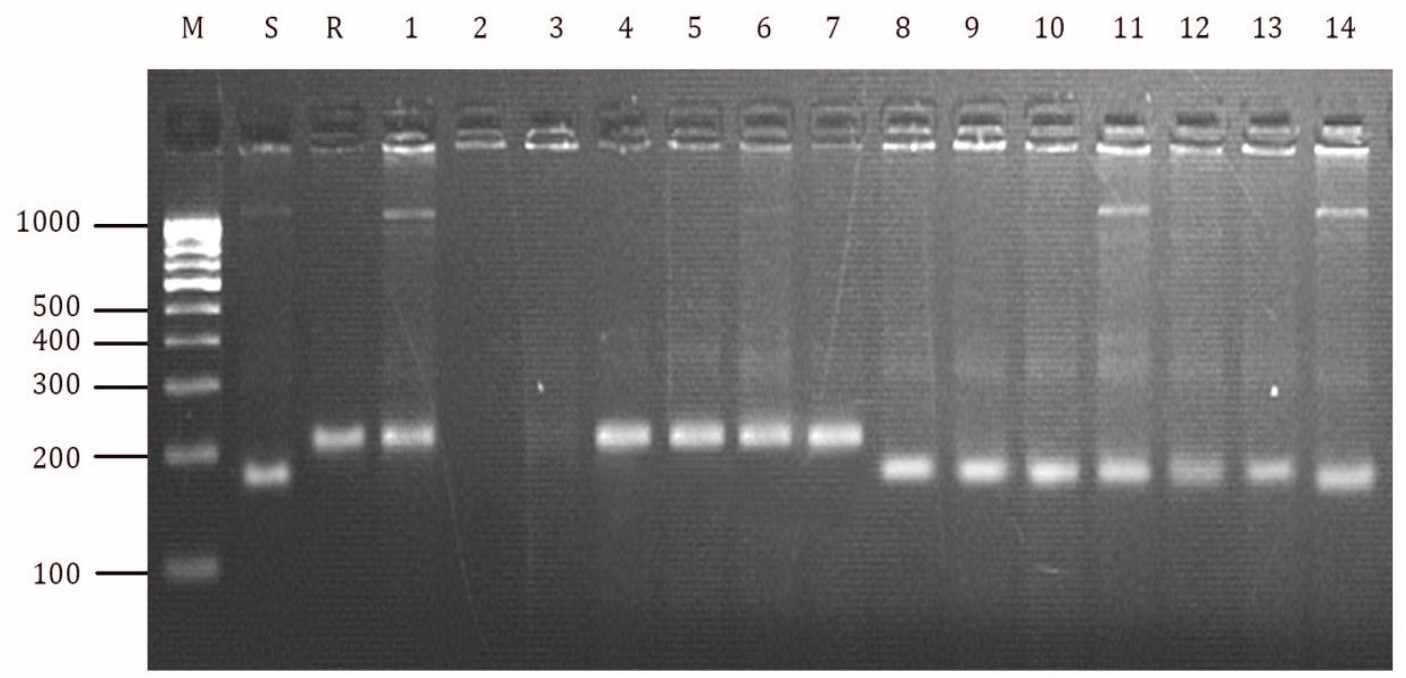

Genotypes, DBW90, WH1021, HD3059, JOB666, UP2843 and WH1124 have proved their suitability for late sown condition out of which the former three genotypes (DBW90, WH1021and HD3059) has already been released for late sown condition. The cluster $\mathrm{V}$, comprising of HD3059 and MACS6272 showed lowest HSI, highest grain yield under late sown and lowest decrease in mean grain yield in late sown condition over timely sown condition, that justifies their recommended cultivation under late sown and rainfed environment. Thus, morphological data of most of the genotypes supported the findings at the molecular level. However, some discrepancies were observed in case of two genotypes i.e., WAXWING and HD2961. WAXWING, which was clustered under terminal heat stress tolerant group showed higher HSI (1.0) and highest percent yield decrease under stress unlike other genotype of the group. Likewise HD2961, which was grouped under sensitive category on the basis of molecular data showed lower value of HSI and lower percent decrease in mean yield that are rather indicative of their inclusion in terminal heat stress tolerant group. The reason for these differences may be that the heat stress is a regional problem. In some areas it shocks the plant for just a few hours and in other areas the stress is prolonged and spans from reproductive stage until the wheat ripens. Also, as heat stress is a complex trait that further combines with another complex trait, yield, the resulting genotype $\times$ environment interaction has a profound impact on the expression of yield trait. Since, the evaluation of the genotypes were conducted under field condition, the weather fluctuation was obvious. The similar results were reported by Pandey et al., (2013).

The heat tolerant wheat variety is emerging priorities of agricultural research, because 
above the optimum temperature $\left(21.3 \pm 1.27^{\circ} \mathrm{C}\right)$ during reproductive stage viz. grain filling duration, wheat yield is drastically affected. Therefore, there is a dire need to develop/identify genotypes that are either tolerant to terminal heat stress or that mature early without appreciable yield losses. Molecular and genetic approaches to study the DNA polymorphism conferring thermotolerance will not only facilitate markerassisted breeding for heat tolerance but also pave the way for cloning and characterization of underlying genetic factors which could be useful for engineering plants with improved heat tolerance. Thus, in a nutshell, in the present investigation, the SSR markers used, proved their worthiness in categorization of the wheat genotypes as terminal heat stress susceptible or tolerant except for fewer anomaly.

\section{References}

Ali, R.A., Kelestanie, A., Asadi, A., Mirfakhraei, S.R., and Abasi, A.R. 2013. Genetic Diversity in Twenty Bread Wheat Cultivars Using Microsatellite Markers. Int. J. Agro. and Plant Production, 4(8): 1920-1927.

Blum, A. 1988. Heat tolerance, In Plant breeding for stress environments. CRCPress.Inc., Boca Raton, Florida, F1.

Bohnert, H.J., Gong, Q., Li, P. and Ma, S. 2006. Unravelling abiotic stress tolerance mechanisms- getting genomics going. Curr. Opin. Plant Biol., 9: 180-188.

Howarth, C.J., 2005. Genetic improvements of tolerance to high temperature. In: Ashraf, M., Harris, P.J.C. (Eds.), Abiotic Stresses: Plant Resistance Through Breeding and Molecular Approaches. Howarth Press Inc., New York.
Joshi S.K., Sharma S.N., 2006. Combining Ability Analysis for Yield and Yield Contributing Characters in Spring Wheat under Late Sown environment. Crop Improv. 33(2): 131-36.

Lobell, D.B., Sibley, A. and OrtizMonasterio, J.I. 2012. Extreme heat effects on wheat senescence in India. Nature Climate Change, 2: 186-189.

Pandey, G.C., Rane, J., Sareen, S., Siwach, P., Singh, N.K. and Tiwari, R. 2013. Molecular investigations on grain filling rate under terminal heat stress in bread wheat (Triticum aestivum L.). African $j$. of Biot., 12(28): 4439-4445.

Pinto, S., Chapman, S.C., McIntyre, C.L., Shorter, R. and Reynolds, M. 2010.For canopy temperature response related to yield in both heat and drought environments. Theor. Appl. Genet., 121(6): 1001-1021.

Rane, J., Pannu, R.K., Sohu, V.S., Saini, R.S., Mishra, B., Shoran, J., Crossa, J., Vargas, M. and Joshi, A.K. 2007. Performance of yield and stability of advanced wheat genotypes under heat stress environments of Indo-Gangetic plains. Crop Sci., 47(4): 1561-1573.

Reynolds, M.P. and Borlaug N.E. 2006.International collaborative wheat improvement: impacts and future prospects. J. Agric. Sci., 144: 3-17.

Reynolds, M.P., Ortiz-Monasterio, J.I. and McNab, A. 2001.Application of Physiology in Wheat Breeding. Mexico D.F., Mexico.

Roder, M.S., Korzun, V., Wendehake, K., Plaschke, J., Tixier, M., Leroy, P. and Ganal, M.W. 1998.A microsatellite map of wheat. Genetics, 149: 2007-2023.

Rohlf, F.G. 1990. NTSYS-PC numerical taxonomy and multivariate analysis system version 1.60.Appl. Biostat., New York.

Sadat, S., Saeid, K.A., Bihamta, M.R., Torabi, S., Salekdeh, S.G.H. and Ayeneh, 
G.A.L. 2013. Marker assisted selection for heat tolerance in bread wheat. World App. Sci. J., 21(8): 1181-1189.

Sairam, R.K. and G.C. Srivastava. 2001. Water stress tolerance of wheat (Triticum aestivum L.): variations in hydrogen peroxide accumulation and antioxidant activity in tolerant and susceptible genotypes. J. of Agronomy and Crop Sci., 186: 63-70.

Wardlaw, I.F., Dawson, I.A. and Munibi, P. 1989. The tolerance of wheat to high temperature during reproductive growth. I. Grain development. Aust. J. Agric. Res., 40: 15-24.

\section{How to cite this article:}

Amarjeet Kumar, Swati, Narendra Kumar Singh, Anil Kumar and Jai Prakash Jaiswal. 2018. DNA Marker Based Characterization of Wheat Genotypes for Terminal Heat Tolerance. Int.J.Curr.Microbiol.App.Sci. 7(03): 2551-2561. doi: https://doi.org/10.20546/ijcmas.2018.703.295 